\title{
Antigenic and genetic characterisation of lipoprotein LppC from Mycoplasma mycoides subsp. mycoides SC
}

\author{
Paola PILO ${ }^{\mathrm{a}}$, Sandra MARTIG ${ }^{\mathrm{b}}$, Joachim FREY ${ }^{\mathrm{a}}$, Edy M. VILEI ${ }^{\mathrm{a} *}$ \\ a Institute for Veterinary Bacteriology, University of Berne, Laenggassstrasse 122, 3012 Berne, \\ Switzerland \\ ${ }^{\mathrm{b}}$ Clinic for Small Animals, University of Berne, Laenggassstrasse 124, 3012 Berne, Switzerland
}

(Received 22 November 2002; accepted 29 April 2003)

\begin{abstract}
Lipoprotein LppC, an immunodominant antigen, and its corresponding gene $\operatorname{lp} p C$ were characterised in Mycoplasma mycoides subspecies mycoides small colony (SC) type, the etiological agent of contagious bovine pleuropneumonia (CBPP). The lppC gene was found in the type strain of M. mycoides subsp. mycoides SC and in field strains isolated in Europe, Africa, and Australia, as well as in vaccine strains. Southern blot analysis indicated the presence of at least four copies of lppC in the genome of M. mycoides subsp. mycoides SC, of which only one seems to be functional. Genes homologous to lppC have also been detected in closely related mycoplasmas such as $M$. mycoides subsp. mycoides large colony (LC) type and in $M$. sp. bovine group 7. LppC is encoded as a precursor with a consensus sequence for a prokaryotic signal peptidase II. The amino acid sequence of LppC and its precursor showed similarity to both LppB (at the N-terminal domain) and LppQ (at the C-terminal domain), two lipoproteins described previously in M. mycoides subsp. mycoides SC. The N-terminal domain of the mature LppC seems to be surface exposed. The $\mathrm{C}$-terminal domain presented an integral membrane structure made up of five repeated units, rich in hydrophobic and aromatic amino acids, which may have pore forming potential in the mycoplasmal membrane. A recombinant peptide representing the N-terminal half of LppC was obtained following cloning in vector pETHIS-1 and expression in Escherichia coli hosts. The recombinant protein was used on immunoblots for serological analysis of sera from cattle that were naturally or experimentally infected with $M$. mycoides subsp. mycoides SC.
\end{abstract}

Mycoplasma mycoides subsp. mycoides SC / contagious bovine pleuropneumonia / multiple copy gene / antigenic protein / lipoprotein

\section{INTRODUCTION}

Contagious bovine pleuropneumonia (CBPP) is an infectious respiratory disease caused by Mycoplasma mycoides subspecies mycoides small colony (SC) type. The disease causes great economic losses in cattle production, primarily in Africa, where the disease is endemic. Due to its significant impact on animal health and livestock production, CBPP is classified as a list-A disease by the Office International des

\footnotetext{
$\ddagger$ These authors contributed equally to this work.

* Corresponding author: edy.vilei@vbi.unibe.ch
} 
Epizooties (OIE), which indexes the most severe contagious animal diseases. CBPP was almost eradicated from Europe in the first half of the 20th century. However, since 1980 the disease has re-emerged in some south European countries. These reemerging outbreaks in Europe were due to a particular cluster of $M$. mycoides subsp. mycoides SC strains which were not present on other continents, as observed by IS 1296 typing [7]. In this respect, small ruminants have been proposed as possible reservoirs of the pathogen [22, 25]. Currently, immunoprophylaxis is based on the use of attenuated live vaccine strains of $M$. mycoides subsp. mycoides SC [20]. These vaccines give relatively short post-vaccinal protective immunity and some doubts about their safety have recently arisen [13]. In order to develop new strategies in the design of vaccines against CBPP, it is essential to understand the molecular mechanisms of the pathogenicity of $M$. mycoides subsp. mycoides SC and to know the nature and function of its antigenic components.

Virulence factors in mycoplasmas seem to be related to structural compounds or metabolic products $[26,27]$. Thus, membrane lipoproteins of several pathogenic mycoplasmas have been suggested as possible virulence factors due to their capability to induce blastogenesis and the secretion of proinflammatory cytokines in vitro [6, $11,21]$.

The major antigenic proteins, as revealed on immunoblots containing total antigen of M. mycoides subsp. mycoides SC and reacted with serum from cows with CBPP, have molecular masses of 110, 98, 9585 , $80,72,62,48,44$, and $39 \mathrm{kDa}[1,9]$. These typical antigens are currently used to confirm sera that were positive in the complement fixation test (CFT) for CBPP. Currently, four lipoproteins of $M$. mycoides subsp. mycoides SC have been characterised. They include LppA (also known as P72), a $72 \mathrm{kDa}$ membrane-located lipoprotein that is also found in Mycoplasma sp. bovine group 7 with only minor differences [8];
LppB, a lipoprotein of $70 \mathrm{kDa}$ which is absent in new European strains of $M$. mycoides subsp. mycoides SC [29]; LppQ, a $48-\mathrm{kDa}$ lipoprotein that appears to be highly specific for the species $M$. mycoides subsp. mycoides SC [2]; and Vmm, a variable surface protein of 59 amino acids that undergoes reversible phase variation [18].

In the present work, we characterised an immunodominant antigen, the putative lipoprotein $\mathrm{LppC}$ and its $\operatorname{lpp} C$ gene in different strains of $M$. mycoides subsp. mycoides SC, as well as gene sequences homologous to $\operatorname{lp} P C$ in other closely related mycoplasmas.

\section{MATERIALS AND METHODS}

\subsection{Strains, growth conditions and DNA extraction}

Strains of M. mycoides subsp. mycoides SC and of the other Mycoplasma species used in this study are listed in Table I. Mycoplasmal cultures were grown in a standard mycoplasma medium [4] to a density of $10^{8}-10^{9}$ cells $/ \mathrm{mL}$. Crude lysate preparations with GES buffer (5 M guanidium thiocyanate, $100 \mathrm{mM}$ EDTA, $0.5 \% \mathrm{~N}$-lauroylsarcosine) and DNA extraction were performed as previously described [7].

For genetic manipulation and subcloning, Escherichia coli strains XL1-Blue MRF' and XLOLR (Stratagene, La Jolla, CA, USA) were used. E. coli strains were grown in Luria-Bertani (LB) broth at $37^{\circ} \mathrm{C}$. The phagemid expression vector $\mathrm{pBK}$ CMV (Stratagene) was propagated in the E. coli strain XLOLR. For subcloning, the pBluescriptII SK ${ }^{-}$vector (Stratagene) was propagated in the E. coli XL1-Blue strain (Stratagene). The pETHIS-1 expression vector [24] was used for poly-histidine fusion at both $\mathrm{N}$-terminal and $\mathrm{C}$-terminal ends of cloned proteins. The E. coli strain BL21(DE3) (Novagen, Madison, WI, USA) was used for expression of recombinant proteins. 
Table I. Mycoplasma strains used.

\begin{tabular}{|c|c|c|c|c|c|c|}
\hline Mycoplasma species & Strain $^{a}$ & Origin & $\begin{array}{l}\text { Year } \\
\text { isolated }\end{array}$ & Host & $\operatorname{lpp} C^{c}$ & $\mathrm{TA}^{e}$ \\
\hline \multirow{23}{*}{$\begin{array}{l}\text { M. mycoides subsp. } \\
\text { mycoides SC }\end{array}$} & PG1 & & 1931 & Cattle/type strain & + & $\underline{8} ; 9 ; 11 ; 17 ; \underline{18}$ \\
\hline & 2059 & Spain & 1984 & Cattle/lung & + & 9 \\
\hline & B773/125 & Portugal & 1991 & Cattle/semen & + & 10 \\
\hline & $\mathrm{C} 305$ & Portugal & 1993 & Goat/lung & + & $10 ; \underline{11}$ \\
\hline & O326 & Portugal & 1993 & Sheep/milk & + & $10 ; \underline{11}$ \\
\hline & PO 2 & France & 1980 & Cattle/lung & + & $\underline{11} ; \underline{12}$ \\
\hline & 2022 & France & 1984 & Cattle/lung & + & 10 \\
\hline & $\mathrm{L} 2$ & Italy & 1993 & Cattle/lung & + & 9 \\
\hline & 402 & Italy & 1990 & Cattle/lung & + & $11 ; \underline{12} ; 13$ \\
\hline & 6479 & Italy & 1992 & Cattle/lung & + & $9 ; \underline{10}$ \\
\hline & Afadé & Cameroon $^{b}$ & 1968 & Cattle/lung & + & $9 ; \underline{10}$ \\
\hline & Fatick & Senegal & 1968 & Cattle & + & $9 ; \underline{10}$ \\
\hline & B17 & Chad & 1967 & Zebu & + & $10 ; \underline{11}$ \\
\hline & $9050-529 / 1$ & Ivory Coast & 1990 & Cattle & + & 10 \\
\hline & 91130 & $\begin{array}{l}\text { Central African } \\
\text { Republic }\end{array}$ & 1991 & Cattle & + & $9 ; \underline{10}$ \\
\hline & 94111 & Rwanda & 1994 & Cattle & + & $12 ; \underline{13}$ \\
\hline & 95014 & Tanzania & 1995 & Cattle & + & 10 \\
\hline & $\mathrm{T} 1 / 44$ & Tanzania & 1952 & $\begin{array}{l}\text { Cattle/vaccine } \\
\text { strain }\end{array}$ & + & $10 ; \underline{11}$ \\
\hline & $\mathrm{T} 1 / \mathrm{Sr} 50$ & Tanzania & 1952 & $\begin{array}{l}\text { Cattle/vaccine } \\
\text { strain }\end{array}$ & + & 9 \\
\hline & Gladysdale & Australia & & Cattle & + & $10 ; 11$ \\
\hline & V5 & Australia & $1965-8$ & $\begin{array}{l}\text { Cattle/vaccine } \\
\text { strain }\end{array}$ & + & 10 \\
\hline & R575 & Australia & $1965-8$ & Cattle & + & 9 \\
\hline & DVZ & Australia & 1965 & Cattle & + & $9 ; \underline{10}$ \\
\hline $\begin{array}{l}\text { M. mycoides subsp. } \\
\text { mycoides LC }\end{array}$ & Y-goat & Australia & & Goat/type strain & + & \\
\hline M. mycoides subsp. capri & PG3 & & & Goat/type strain & $++^{d}$ & \\
\hline $\begin{array}{l}\text { Mycoplasma sp. bovine } \\
\text { group } 7\end{array}$ & PG50 & Australia & & $\begin{array}{c}\text { Cattle/reference } \\
\text { strain }\end{array}$ & + & \\
\hline $\begin{array}{l}\text { M. capricolum subsp. } \\
\text { capricolum }\end{array}$ & California kid & California & & Goat/type strain & - & \\
\hline $\begin{array}{l}\text { M. capricolum subsp. } \\
\text { capripneumoniae }\end{array}$ & F38 & Kenya & & Goat/type strain & - & \\
\hline M. agalactiae & PG2 & Spain & 1973 & Goat/type strain & - & \\
\hline M. bovis & PG45 & & & Cattle/type strain & - & \\
\hline M. putrefaciens & KS1 & & & Goat/type strain & - & \\
\hline
\end{tabular}

${ }^{a}$ Collections: the strains were obtained from the National Collection of Type Cultures (NCTC), PHLS, London, United Kingdom; Laboratoire de Pathologie Bovine, Lyon, France; Laboratório Nacional de Veterinaria, Lisbon, Portugal; CIRAD-EMVT, Montpellier, France; Institute for Veterinary Bacteriology, University of Berne, Berne, Switzerland; and Australian Animal Health Laboratory, Geelong, Victoria, Australia.

${ }^{b}$ Isolated at Farcha Laboratory, N'Djaména, Chad, from a bovine from Afadé, Northern Cameroon.

${ }^{c}$ As tested by Southern blot hybridisation with the gene probe $\mathrm{C} 2$; - indicates no hybridisation signal.

${ }^{d} \mathrm{~A}$ very faint band reacted with the gene probe $\mathrm{C} 2$.

${ }^{e}$ Number of TA repeats in the promoter area of $\operatorname{lpp} C$. Note the presence of a variable number of dinucleotide repeats within the same strain, indicating a heterogeneous mycoplasma population. Underlined numbers refer to the predominant variants for each strain. 


\subsection{DNA manipulation, construction and screening of an expression library}

DNA of the M. mycoides subsp. mycoides SC Afadé strain was partially digested with Sau3AI to obtain fragments ranging from 2 to $10 \mathrm{~kb}$. DNA fragments were ligated with BamHI-digested $\lambda$ Zap Express cloning vector (Stratagene), and packaged with Gigapack II packaging extract (Stratagene). The library was plated according to the manufacturer's protocol using the $E$. coli host strain XL1-Blue MRF'. Screening of the library was performed following a standard protocol with serum from a cow experimentally infected with the Afadé strain (cow \#512, serum taken at slaughter, 42 days post-infection) [1] used at a dilution of 1:100. Positive clones were selected, amplified and excised in vivo into $\mathrm{pBK}$ CMV phagemids using the filamentous helper phage ExAssist (Stratagene) as indicated by the manufacturer.

A partial genomic library of the $M$. mycoides subsp. mycoides SC L2 strain was made by cloning total DNA digested with HindIII into the HindIII site of the pBluescriptII SK ${ }^{-}$vector. Clones were selected by colony screening with the digoxigenin11-dUTP-labelled $\mathrm{C} 2$ gene probe produced by PCR using oligonucleotide primers MMMSCAFIIC1 and MMMSCAFIIC2 (Tab. II) designed against part of the $\operatorname{lpp} C$ gene [19]. Plasmid DNA of selected colonies were isolated using the QIAprep ${ }^{\mathrm{TM}}$ Spin Miniprep kit (Qiagen AG, Basle, Switzerland).

\subsection{Molecular biology techniques and bioinformatic analysis}

PCR reactions and the Southern blot analysis were performed as described previously [19] with the specific primers listed in Table II.

Amplified $l p p C$ products, obtained with primers MMMSCL 7 and MMMSCAFIIC7 from the 23 M. mycoides subsp. mycoides SC strains tested (Tab. I), were cloned into the pGEM-T vector (Promega, Madison, WI, USA) and the constructs were subsequently propagated in the $E$. coli XL1-Blue strain. Plasmid DNA of six randomly selected colonies for each strain was isolated and subjected to sequencing.

DNA sequencing and analysis were performed as previously described by Abdo et al. [1]. Alignments were performed with the Wisconsin package (Genetics Computer Group, Inc. [GCG], Madison, WI, USA) and with the ClustalW 1.8 and BOXSHADE 3.21 programs both from EMBnet.ch (http:// www.ch.embnet.org/index.html). Transmembrane prediction of the protein was made by using TMpred (http://www.ch.embnet.org/ software/TMPRED_form.html) [12] and by the method of Kyte and Doolittle [14].

\subsection{Production of poly-histidine-tailed fusion protein LppC}

A poly-histidine-tailed LppC fusion protein was obtained by amplification of the $\mathrm{N}$-terminal part of LppC, from amino acid 24 to amino acid 254, using genomic DNA of the Afadé strain and the primers MMMSCL1 and MMMSCL2 (Tab. II), containing a HindIII and a NotI restriction site overhang, respectively. The PCR product was digested by HindIII and NotI and cloned into $\mathrm{pETHIS}-1$. The resulting plasmid pJFFLppC-His was verified by restriction enzyme digestion and partial DNA sequencing. Expression and purification of poly-histidine tailed LppC was made as described previously for lipoprotein LppB [29]. The recombinant protein had an apparent molecular mass of approximately $32 \mathrm{kDa}$ (data not shown) which corresponded to the calculated mass of $31.4 \mathrm{kDa}$ for LppCN'-His.

\subsection{CBPP sera and production of monospecific rabbit anti-LppCN'-His antibodies}

Sera taken sequentially from cattle that had undergone a controlled experimental 
Table II. Oligonucleotide primers used in this study.

\begin{tabular}{|c|c|c|c|}
\hline Name & Sequence $^{a}$ & Position $^{b}$ & $\begin{array}{l}\text { Annealing } \\
\text { temp. }\left({ }^{\circ} \mathrm{C}\right)^{c}\end{array}$ \\
\hline MMMSCAFIIC1 & TGTTGGTTTAGTTGCAACAAC & $1156-1176$ & 49.5 \\
\hline MMMSCAFIIC2 & СТCССТAAACGTAATTTAACC & $1566-1546$ & 48.6 \\
\hline MMMSCAFIIC3 & ACGTTTTGTTGAGTTAAAAATGG & $2935-2913$ & 50.1 \\
\hline MMMSCAFIIC4 & TGTTCAGTTATCATCTGCAAG $^{d}$ & & 48.5 \\
\hline MMMSCAFIIC5 & TTTCTGCAGACTTAGTACTTG & $1232-1212$ & 47.6 \\
\hline MMMSCAFIIC6 & AAAAAATTCTGAGGTCATAAAAG & $1357-1379$ & 49.0 \\
\hline MMMSCAFIIC7 & AAAACTGGCCATCTTGATCTTC & $1676-1655$ & 50.4 \\
\hline MMMSCAFIIC8 & AAAATGTAGTTATTACTCAAATAG & $1698-1721$ & 47.1 \\
\hline MMMSCAFIIC10 & CCACAGACCATAGTAAAAGC $^{d}$ & & 48.3 \\
\hline MMMSCAFIIC11 & GCTATGCTCTATCTTATTTTTTG $^{d}$ & & 48.6 \\
\hline MMMSCAFIIC12 & ACAAATGTAACCAACAATATGG $^{d}$ & & 49.0 \\
\hline MMMSCL1 & GTaagcttTTGTGGTGATAAAACACCAAGT & $1187-1216$ & $49.8^{\mathrm{e}}$ \\
\hline MMMSCL2 & GAgcggccgcATTTATCTAAGTTTAAAACTTCTTT & $1899-1865$ & $47.8^{\mathrm{e}}$ \\
\hline MMMSCL3 & CTAACCCGCAAACTTCAAACC & $256-276$ & 51.0 \\
\hline MMMSCL4 & GATCCTTTTCCGTTCTCATAATC & $803-781$ & 50.0 \\
\hline MMMSCL5 & GCTGCTGCAACAAAGTTTAACC & $2003-2024$ & 51.1 \\
\hline MMMSCL6 & GGAGATTCTGAATTTTGATTATTG & $361-338$ & 49.7 \\
\hline MMMSCL7 & ATAATGCTGTTTCTCAATTAAAAG & $697-720$ & 49.1 \\
\hline MMMSCL8 & GGTTAAAATCTGTTGCATCATAG & 2099-2077 & 49.4 \\
\hline MMMSCL9 & TACTGTCTTAGGTATTAATAGC & $2557-2536$ & 46.5 \\
\hline MMMSCL10 & GGAAAAGACTTGTTTTAAAAAAC & $2588-2610$ & 49.1 \\
\hline MMMSCL11 & AACGGAAAAGGATCTGGATCTG & $790-811$ & 51.1 \\
\hline MMMSCL12 & TACAACCAACATATTTTTCTTTC & $1754-1732$ & 49.7 \\
\hline
\end{tabular}

${ }^{a}$ Lower-case letters indicate nucleotides added to create restriction enzyme recognition sites for cloning.

${ }^{b}$ Based on nucleotide sequence AY026041 (3.1-kb insert of plasmid pJFFL2IA, the insert deriving from the European strain L2).

${ }^{c}$ Obtained with the 'PCR primer annealing temperature calculator' developed by J. Boxall on the web page http://www.res.bbsrc.ac.uk/biochem/oligos/input.html, by using the parameters $30 \%$ as the target GC content and $1000 \mathrm{bp}$ as the target size.

$d$ Primers designed on the insert of plasmid pJFFAfIIC2.

$e$ Not considering the nucleotides added to create the restriction enzyme recognition site.

infection with M. mycoides subsp. mycoides SC, the European strain L2 (cow \#502) and African strain Afadé (cows \#511 and \#512), which have been described in detail [1]. Sera from cows that were naturally infected were obtained from F. Santini, Teramo, Italy and F. Poumarat, Lyon, France and had CFT titers ranging from $1: 10$ to $1: 1280$.
Monospecific, polyclonal antibodies directed against LppCN'-His were obtained by immunising a rabbit subcutaneously with approximately $40 \mu \mathrm{g}$ of recombinant polyhistidine-tailed LppC in $450 \mu \mathrm{L}$ saline buffer (50 mM NaH${ }_{2} \mathrm{PO}_{4}, \mathrm{pH} 8.0,0.85 \%$ $\mathrm{NaCl}$ ) mixed with $450 \mu \mathrm{L}$ Freund complete adjuvant (Difco Laboratories, Detroit, MI, USA). Two booster immunisations with 
approximately the same amount of protein in Freund incomplete adjuvant (Difco Laboratories) were performed 21 days and 33 days after the first injection. The animal was bled 16 days after the second booster immunisation, according to standard protocols [10] and rabbit antiserum against LppCN'-His was collected.

\subsection{Immunoblot analysis and Triton X-114 partitioning}

Proteins were separated by 10 or $12 \%$ SDS polyacrylamide gel electrophoresis (SDS-PAGE) as described by Laemmli [15] and transferred onto nitrocellulose membranes (BioRad Laboratories, Hercules, CA, USA) according to standard protocols [3]. For immunoblotting, Western blots were blocked with $1 \%$ milk buffer for at least one hour and then incubated with the rabbit antiserum against $\mathrm{LppCN}$ '-His $(1: 1000)$ or different CBPP sera $(1: 100)$ in milk buffer overnight at $4{ }^{\circ} \mathrm{C}$ on a shaker. The membranes were then washed thoroughly with deionised water before incubation with alkaline phosphatase-labelled conjugates goat anti-rabbit IgG $(\mathrm{H}+\mathrm{L})$ (Kirkegaard \& Perry, Gaithersburg, MD, USA) or monoclonal anti-bovine $\mathrm{IgG}$ (Sigma Chemical Co., St. Louis, MO, USA) diluted 1:2000 and 1:5000 in 1\% milk buffer, respectively, for $90 \mathrm{~min}$ at room temperature. The colour reaction was initiated by the addition of nitroblue tetrazolium and bromochloroindolyl phosphate in alkaline substrate buffer $\left(7 \mathrm{mM} \mathrm{Na}_{2} \mathrm{CO}_{3}\right.$, $3 \mathrm{mM} \mathrm{NaHCO}_{3}$, pH 9.6, $1 \mathrm{mM} \mathrm{MgCl}$ ).

Immunostaining on colony plaque fingerprints was performed by a modification of the method described by Persson et al. [18]. Briefly, between 10000 and 50000 colony plaques of $M$. mycoides subsp. mycoides SC strains PG1, O326, L2, Afadé and T1/Sr50 were grown on agar plates and transferred onto nitrocellulose membranes by placing the membranes on the surface of agar plates. The membranes were gently removed and blocked with $1 \%$ milk buffer prior to immunoblot- ting with the monospecific anti-LppCN' serum (1:1000).

$M$. mycoides subsp. mycoides SC total antigen was separated into hydrophobic and hydrophilic fractions by the Triton X114 partitioning method [5] using a $10-\mathrm{mL}$ culture of Afadé grown until the stationary phase. Samples from the Triton X-114 detergent phase, the aqueous phase, and whole mycoplasma cells were mixed with protein sample buffer, run on SDS-acrylamide gels, and blotted onto nitrocellulose. The filter was subsequently used for immunoblotting with the monospecific, polyclonal antibodies directed against LppC.

\subsection{Nucleotide sequence accession numbers}

The EMBL/GenBank accession number of the cloned fragment containing the lppC gene of plasmid pJFFL2IA from $M$. mycoides subsp. mycoides SC L2 strain is AY026041. Sequence data of the $\operatorname{lppC}$ gene of plasmid pJFFAfIIC2 from Afadé are accessible under AY026042.

\section{RESULTS}

\subsection{Cloning and sequence analysis of $\operatorname{lppC}$ from $M$. mycoides subsp. mycoides SC}

An expression library based on the bacteriophage vector Zap Express was obtained from genomic DNA of the $M$. mycoides subsp. mycoides SC Afadé strain. Phage clones were screened using serum from a cow experimentally infected with $M$. mycoides subsp. mycoides SC. One clone out of 5000 , named pJFFAfIIC2 (Fig. 1), reacted strongly with the CBPP serum and was selected for DNA sequence analysis. It contained a $4.2 \mathrm{~kb}$ insert and revealed the presence of part of a gene encoding a potential lipoprotein named LppC; the gene was designated $\operatorname{lppC}$. PCR analysis with primers MMMSCAFIIC1/MMMSCAFIIC3 
A
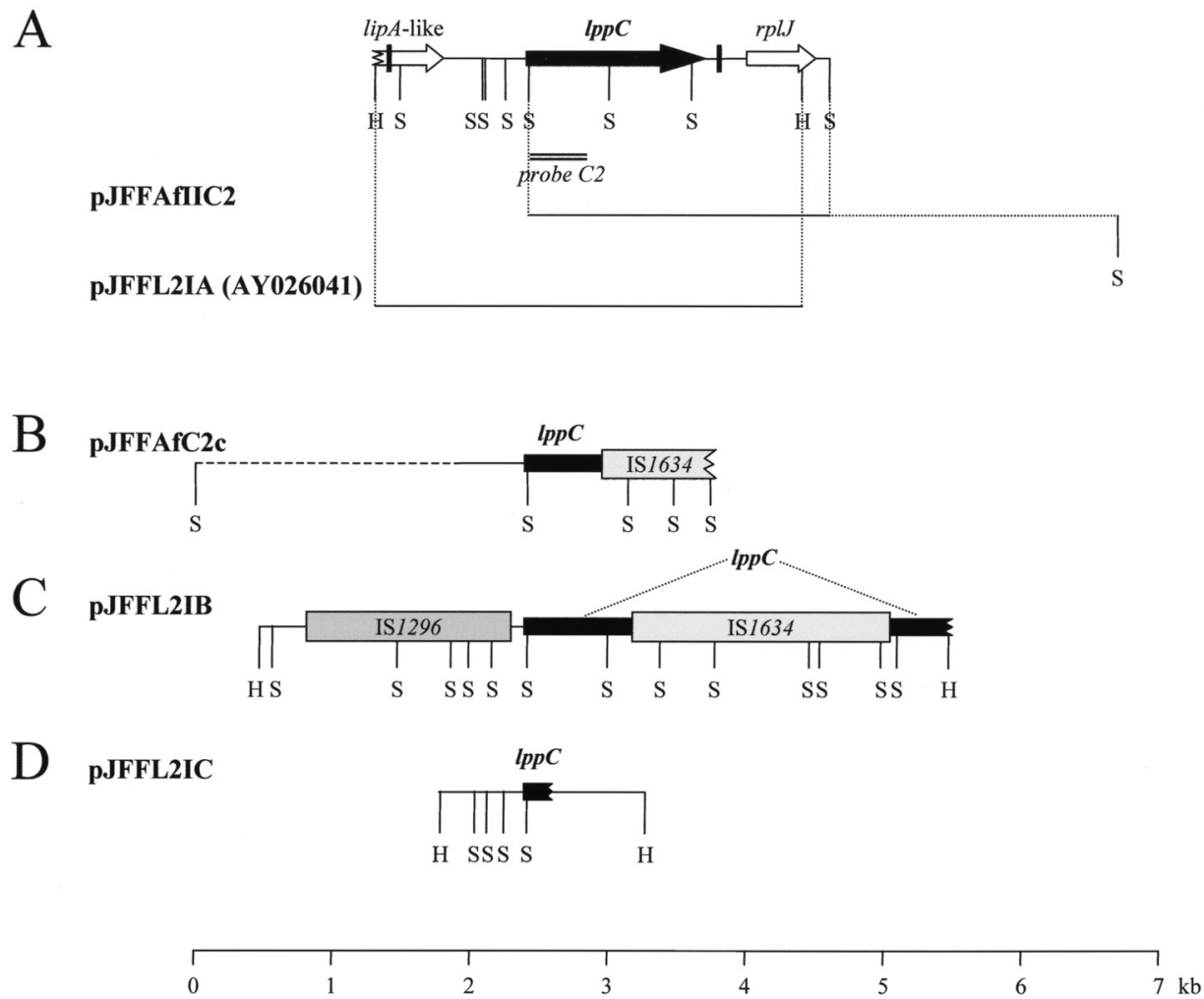

Figure 1. Plasmids investigated in this study. The four $\operatorname{lpp} C$ genes found are the complete, functional copy $(A)$; the IS1634-disrupted copies $(B$ and $C)$; and the truncated form $(D)$. Clones pJFFL2IA, pJFFL2IB and pJFFL2IC were derived from a plasmid bank created with HindIIIdigested genomic DNA from the M. mycoides subsp. mycoides SC strain L2. Both clones pJFFAfIIC2 and pJFFAfC2c derive from a phage bank created with Sau3AI-digested genomic DNA of the Afadé strain. H, the cut site of HindIII; and S, the cut site of Sau3AI. Vertical black bars represent the 85-bp direct repeats. The dotted line indicates the non-contiguous half of pJFFAfIIC2 and the interrupted line indicates the non-sequenced portion of pJFFAfC $2 \mathrm{c}$. The localisation of the gene probe $\mathrm{C} 2$ is indicated. The genetic maps are aligned with the $5^{\prime}$ end of the functional $\operatorname{lpp} C$ (plasmid pJFFL2IA).

and MMMSCAFIIC1/MMMSCAFIIC4 (Tab. II) revealed the integrity of the clone. The remaining part of lppC was then obtained using PCR technology. By screening the expression library with the specific $\mathrm{C} 2$ probe (Fig. 1) plasmid pJFFAfC2c was obtained and was found to contain part of another copy of $\operatorname{lpp} C$ that was interrupted by the insertion sequence IS1634 (Fig. 1).
To investigate the presence of $\operatorname{lpp} C$ genes in a re-emerging European strain of M. mycoides subsp. mycoides SC, a plasmid gene bank was produced with HindIII digested genomic DNA of L2 strain and screened with the $\mathrm{C} 2$ probe. Three positive clones, plasmids pJFFL2IA, pJFFL2IB, and pJFFL2IC, were selected (Fig. 1). Sequence analysis revealed that the pJFFL2IA insert 
consisted of a contiguous segment that corresponded exactly to the DNA segment carried by pJFFAfIIC2 (Fig. 1). It contained an open reading frame (ORF) of $1236 \mathrm{bp}$, encoding a protein of 411 amino acids with a calculated molecular mass of $47.3 \mathrm{kDa}$. The coding sequence of $\operatorname{lpp} C$ contains 7 mycoplasma-specific TGA Trp $_{\text {codons. }}$.

The lppC ORF is preceded by a consensus sequence for a putative ribosomal binding site located 5 nucleotides upstream of the start codon, a possible -10 box (TATAATG) located 43 nucleotides upstream of the start codon, and a possible -35 box (TTGACA) located another 16 nucleotides upstream of the -10 box. No significant stem loop structure was found downstream of the stop codon. Further downstream, we identified the rplJ gene encoding the ribosomal 50S subunit protein L10. Upstream of the $\operatorname{lppC}$ gene, we detected the 3'-terminal part of a putative gene resembling the lipA gene of M. pulmonis and a stem loop structure with a $\Delta G$ of $-5.8 \mathrm{kcal} / \mathrm{mol}$ representing a potential transcription stop signal.

Two 85-bp direct repeats were detected on plasmid pJFFL2IA (Fig. 1). The first one was located in the lipA-like ORF upstream of $\operatorname{lpp} C$ beginning at base 47 and ending at base 131 of the 3337-bp sequence. The second one was found in the non-coding region downstream of the $\operatorname{lpp} C$ gene beginning at base 2387 and ending at base 2471. The sequences of the 40 bases flanking both repeats on their 5 ' ends were very similar. The 35 bases forming the 3' ends of these two direct repeats were identical to a portion of IS1296, with the exception of one nucleotide substitution.

Even though the coding regions of $\operatorname{lp} p C$ in M. mycoides subsp. mycoides SC strains Afadé and L2 were identical, two differences were found on the segments flanking lppC. A poly-G region, beginning 104 nucleotides downstream of the $\operatorname{lpp} C$ gene contains eight G's in L2 strain and only seven in the Afadé strain. The other difference found in the L2 strain compared to the Afadé strain was located in the promoter area 46 nucleotides upstream of the start codon of the $\operatorname{lpp} C$ gene. There, a polymorphism was found in a poly-TA sequence flanked by two inverted repeats (ACAT and ATGT). This palindromic sequence included the last three bases of the possible -35 box and the whole putative -10 box of the gene $\operatorname{lppC}$ and formed a stem loop structure with a $\Delta G$ of $-9.6 \mathrm{kcal} / \mathrm{mol}$. The $\mathrm{L} 2$ strain possesses nine TA dinucleotides while genomic DNA of the Afadé strain has principally ten. PCR amplification with primers MMMSCL7 and MMMSCAFIIC7 (Tab. II) for all strains followed by cloning and sequencing with primers MMMSCL11 and MMMSCAFIIC2 (Tab. II) revealed that the number of TA repeats in this locus varied from 8 to 18 copies (Tab. I). Moreover, DNA sequencing of these cloned fragments containing the $\operatorname{lp} P C$ promoters of given strains revealed that the number of TA repeats varies within almost each strain, indicating the occurrence of mycoplasma subpopulations with a polymorphism in the lppC promoter region.

\subsection{Analysis of the amino acid sequence of the lipoprotein $\mathrm{LppC}$}

Sequence analysis of the amino acid sequence deduced from the $\operatorname{lppC}$ gene revealed significant similarity with the hypothetical surface-located membrane protein LppB of M. mycoides subsp. mycoides SC (EMBL/GenBank accession number AF165135), showing 37\% identity and $49 \%$ similarity, and with the membrane associated lipoprotein precursor LppQ of M. mycoides subsp. mycoides SC (EMBLGenBank accession number AF072716), showing $31 \%$ identity and $47 \%$ similarity. Analysis of the amino acid sequence of LppC revealed a typical prokaryotic signal peptidase II cleavage site in the $\mathrm{N}$-terminal region containing two Lys residues in the first seven amino acids. The peptidase cleavage site consists in Val-Ile-Ala_CysGly, the cystein residue being at position 24 . Hence, the resulting mature LppC protein of 388 amino acids had a calculated 


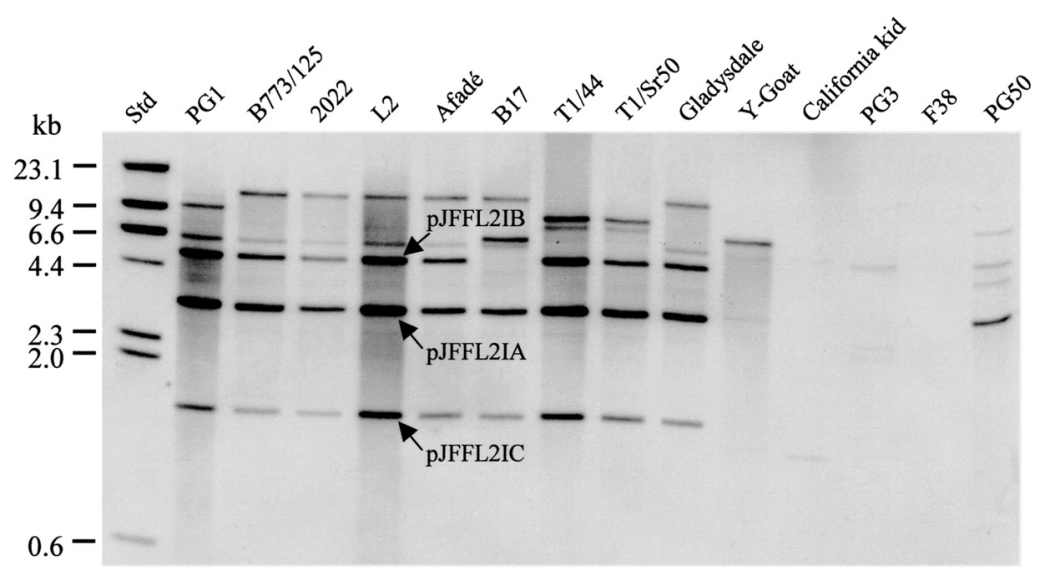

Figure 2. Detection of individual copies of $\operatorname{lpp} C$ in a selection of strains of $M$. mycoides subsp. mycoides SC and other mycoplasma species by Southern hybridisation. Three hundred nanograms of genomic DNA were digested with HindIII, separated electrophoretically on $0.7 \%$ agarose gels, transferred onto positively charged nylon membranes, and hybridised to the DIG-labelled $\operatorname{lpp} C \mathrm{C} 2$ probe. The bands corresponding to full or partial $\operatorname{lp} p C$ genes as cloned in pJFFL2IA, pJFFL2IB and pJFFL2IC are indicated by arrows. Std, molecular mass standards $(23.1,9.4,6.6,4.4,2.3,2.0$, and $0.6 \mathrm{~kb})$.

molecular mass of $45.1 \mathrm{kDa}$. The leader sequence showed a typical transmembrane helix structure, where TMpred identified a unique and significant transmembrane region (score 1814) spanning amino acids 4 to 22 in the N-terminal domain of the protein. Hydrophilicity analysis of the amino acid sequence of the non-cleaved LppC revealed that the first 25 amino acids of the $\mathrm{N}$-terminal end were the most hydrophobic part of the molecule. The region following this part until amino acid 80 was particularly hydrophilic while the rest of the protein was slightly hydrophilic with little hydrophobic regions. Moreover, the C-terminal domain of LppC was shown to be built up of five repeated units composed of 25 amino acids, rich in hydrophobic and aromatic residues (Trp-X[4]-[Val/Ile]$\mathrm{X}$ [2]-[Met/Leu]-X[2]-Met-Phe-X[5]-PheAsn-X[2]-[Ile/Leu]-X[2]) with a substitution of the twelfth amino acid (Met) by a Leu residue in the second repeat and a substitution of the twentieth amino acid (Asn) also by a Leu residue in the fifth repeat.
These repeats also supported an integral membrane location of the $\mathrm{C}$-terminal part of LppC.

\subsection{Evidence for multiple copies of the $\operatorname{lpp} C$ gene in the $M$. mycoides subsp. mycoides $\mathrm{SC}$ genome}

Sequence analysis of the $\operatorname{lpp} C$ gene and the flanking genes of the individual clones from the Afadé and L2 strains revealed significant differences to the $\operatorname{lp} C \mathrm{C}$ gene on plasmids pJFFL2IA and pJFFAfIIC2 (Fig. 2), indicating three additional but incomplete $\operatorname{lpp} C$ genes. One copy of the lppC gene, found on plasmid pJFFAfC $2 \mathrm{c}$, had only a few base changes in 475 nucleotides of the 5'-terminal part, but the 3'-terminal part of the gene was completely missing. In this case, a copy of the insertion element IS1634 was found downstream of position 475 of the $\operatorname{lpp} C$ gene (Fig. 1). A second copy, represented by plasmid pJFFL2IB, had an incomplete $\operatorname{lp} p C$ gene that was interrupted by another copy of 


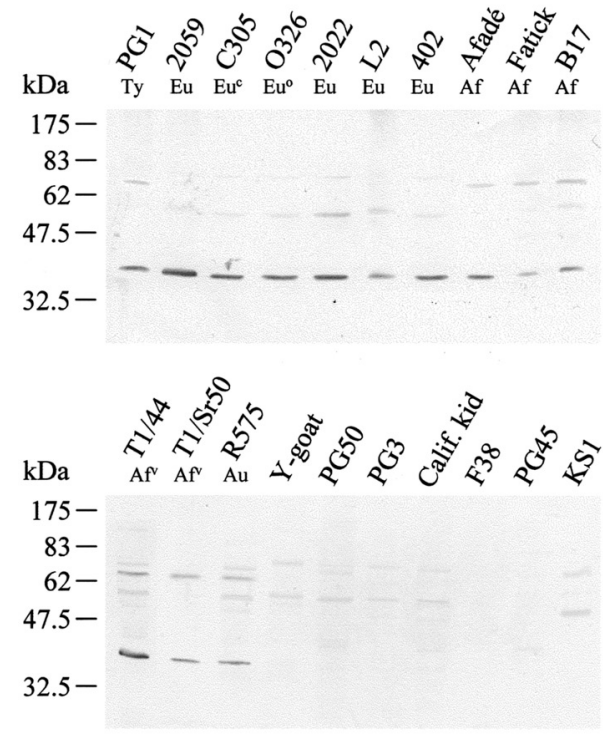

Figure 3. LppC expression in M. mycoides subsp. mycoides SC and related mycoplasmas. Immunoblot analysis was carried out with $10 \mu \mathrm{g}$ of total antigen in each lane. Total antigen of all mycoplasmas tested was separated by SDS/12\% acrylamide gels, transferred onto nitrocellulose membranes, and probed with the antiserum against LppC.

IS1634 at position 786 (Fig. 1). Finally, a third copy, represented by plasmid pJFFL2IC, contained only a small part (approximately 190 nucleotides) of the 5' domain of lppC (Fig. 1). These observations led to the conclusion that $\operatorname{lpp} C$ is present in more than one copy in the genome of $M$. mycoides subsp. mycoides SC. To confirm this, Southern blot analysis was done on genomic DNA from all $M$. mycoides subsp. mycoides SC strains and related mycoplasmas digested with HindIII. Detection of the $\operatorname{lppC}$ gene was performed with the gene probe C2 (Fig. 1, Tab. I). All M. mycoides subsp. mycoides SC strains tested showed the expected reacting band for the functional $\operatorname{lp} p C$ gene at $3.1 \mathrm{~kb}$, corresponding to the part cloned in plasmid pJFFL2IA, as well as a band at $1.5 \mathrm{~kb}$ which corresponded to the partial
lppC gene on the HindIII fragment in plasmid pJFFL2IC (Fig. 2). Moreover, almost all strains presented a band at $5.0 \mathrm{~kb}$, corresponding to the partial $\operatorname{lpp} C$ gene in plasmid pJFFL2IB (Fig. 2). Only one African strain (B17), isolated from a zebu, had a singular hybridisation pattern showing a band at $7.0 \mathrm{~kb}$ instead of $5.0 \mathrm{~kb}$. The $\mathrm{C} 2$ probe reacted faintly with two other bands of all $M$. mycoides subsp. mycoides SC strains. One of these HindIII fragments was thought to correlate with the IS1634-truncated lppC copy found in plasmid pJFFAfC2c. The fifth fragment might be related to another unknown truncated form of $\operatorname{lppC}$ or to a similar lipoprotein gene. The $\mathrm{C} 2$ probe also showed a weak hybridisation signal with DNA from the M. mycoides subsp. mycoides LC type strain Y-goat. The $M$. sp. bovine group 7 reference strain PG50 showed a strongly reacting band at $3.1 \mathrm{~kb}$ which harbours an $\operatorname{lp} p C$-like gene. This $\operatorname{lppC}$ homologue presented $83 \%$ identity in 577 nucleotides of the 5 ' end with the $\operatorname{lpp} C$ gene of plasmid pJFFL2IA. At the amino acid level, this corresponded to $73.5 \%$ identity and $87 \%$ similarity in a portion of 189 amino acids.

\subsection{Expression of LppC in M. mycoides subsp. mycoides SC}

All M. mycoides subsp. mycoides SC strains reacted with anti-LppCN'-His antibodies on immunoblots revealing a distinct band at $39 \mathrm{kDa}$ (Fig. 3). In addition, the blots also revealed a band at $70 \mathrm{kDa}$ crossreacting with anti-LppCN'-His in all strains except in those from Europe. The other mycoplasma species did not react with anti-LppCN'-His antibodies (Fig. 3). In a control experiment using the same antigen preparations, we observed expression of LppQ in all M. mycoides subsp. mycoides SC strains tested. Analysis of immunostained colonies of $M$. mycoides subsp. mycoides SC strains using antiLppC serum did not reveal any non-stained sectors, indicating that $\mathrm{LppC}$ is not a variable antigen. 


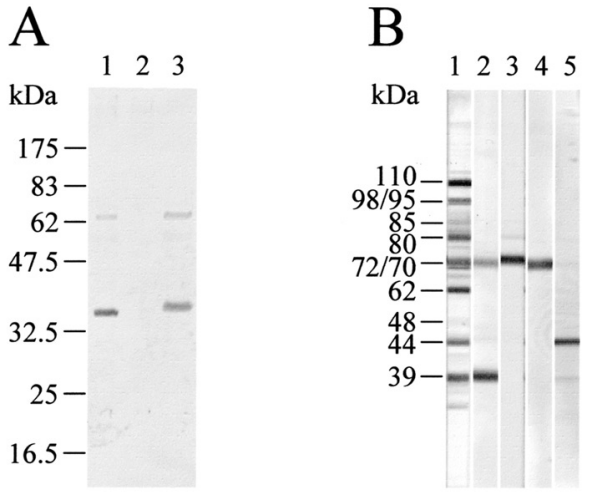

Figure 4. Triton $\mathrm{X}-114$ phase partitioning of the $M$. mycoides subsp. mycoides SC Afadé strain. (A) Mycoplasmas at the end of exponential growth were submitted to Triton X-114 partitioning; $15 \mu \mathrm{L}$ of fractions and total antigen were separated by SDS/12\% acrylamide gels, transferred onto a nitrocellulose filter, and probed with monospecific LppC antiserum. Lane1, total antigen; lane 2, aqueous phase; lane 3 , detergent phase. (B) Western blot analysis of Triton X-114 extract from Afadé using antiserum from cow \#512 at day 35 (CFT titer of 1:10240) post-infection with the Afadé strain (lane 1) and monospecific rabbit antibodies against LppC (lane 2), LppA (P72) (lane 3), LppB (lane 4) and LppQ (lane 5).

\subsection{Identification of $\mathrm{LppC}$ as a membrane protein}

To determine the cellular location of LppC, total antigen of the M. mycoides subsp. mycoides SC Afadé strain was submitted to Triton X-114 phase partitioning. Monospecific anti-LppC serum reacted strongly with a $39-\mathrm{kDa}$ protein and weakly with a 70-kDa protein in the Triton X-114 phase but not with any proteins found in the aqueous phase (Fig. 4A). This indicates that $\mathrm{LppC}$ is an integral membrane protein. This corresponds to calculations based on the amino acid sequence of LppC, as mentioned before. Western blot analysis of the Triton X-114 extract with serum from a cow experimentally infected with the Afadé strain showed one band of approximately $39 \mathrm{kDa}$ corresponding to $\mathrm{LppC}$
(Fig. 4B). Immunoblots with the monospecific antibodies against LppA (P72), LppB and LppQ, which were used as controls, revealed similar reaction strengths as found with the anti-LppCN' serum. Furthermore, anti-LppB antibodies revealed a band at $70 \mathrm{kDa}$ that migrated to the same position on the gel as the $70-\mathrm{kDa}$ band reacting with the anti-LppCN' antibodies.

\subsection{Immunogenicity of LppC}

Membrane strips containing the recombinant LppCN'-His protein were reacted with sera from cattle, taken sequentially before and after experimental contact infection with M. mycoides subsp. mycoides SC strains L2 (cows \#502) and Afadé (cow \#511), respectively. The infection of these two cows was performed by housing them in contact with inoculated animals. Serum from cow \#502 gave a weak signal at 126 days post-infection. This signal persisted albeit at lower levels until 224 days of infection (Fig. 5A). In the case of cow \#511, the first serum showing a positive reaction to LppCN'-His was the one collected 49 days post-infection. Strong signals could be detected with sera collected between days 56-98 post-infection. Afterwards, the signals weakened but were still easily detectable until the serum taken at slaughter 147 days post-infection (Fig. 5B). Analysis of sera from naturally infected European cattle gave strong serological reactions with recombinant LppCN'-His, except for a weakly positive serum (gamma) with a CFT titer of 1:10 (Fig. 5C).

\section{DISCUSSION}

Western blot analysis using sera from cattle with CBPP revealed proteins with the molecular masses of $110,98,95,85,80,72$, $62,48,44$, and $39 \mathrm{kDa}$ as the most common antigenic bands among all $M$. mycoides subsp. mycoides SC strains [1,9]. The group constituting African and Australian strains and the type strain PG1 was also 


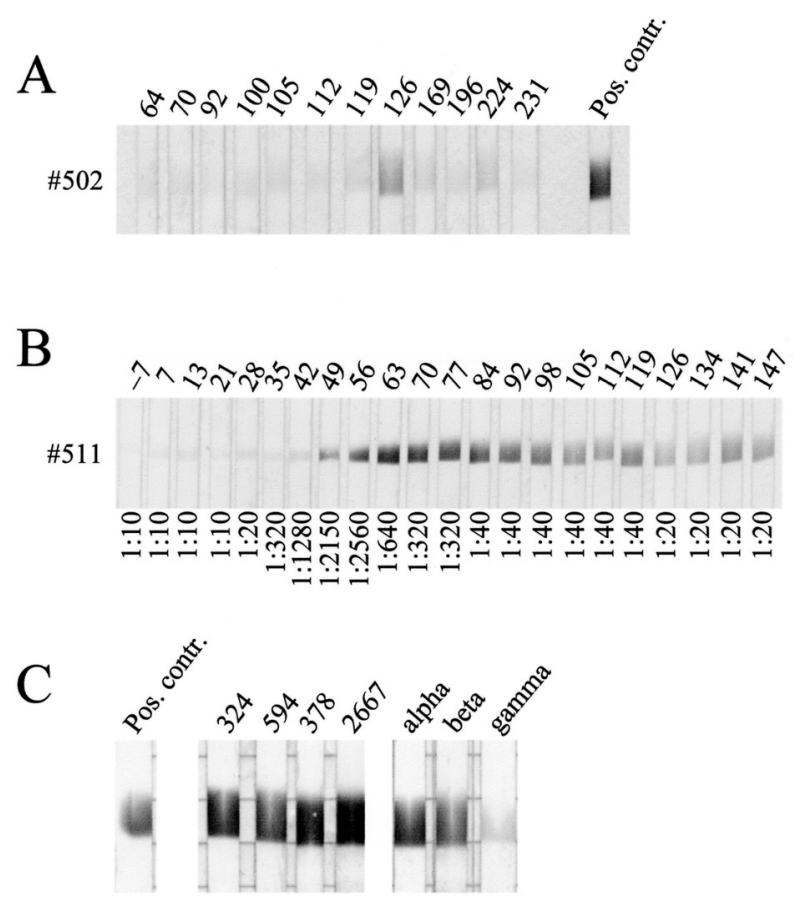

Figure 5. Appearance of antibodies against $\mathrm{LppC}$ during experimental and natural infections with M. mycoides subsp. mycoides SC. The immunoblots contain purified recombinant LppCN'-His and were reacted with cow sera taken sequentially before and after experimental infection with the L2 and Afadé strains, or with European CBPP sera. (A) LppCN'-His reacted with serum from cow \#502 contact infected with L2. The numbers on the top of each row indicate days after infection. (B) LppCN'-His reacted with serum from cow \#511 contact infected with Afadé. The CFT titers for sera from cow \#511 are given at the bottom of each row. The numbers on the top of each row indicate days before (-) or after infection. (C) LppCN'-His reacted with seven CBPP sera from France and Italy. Sera 324, 594, 378 and 2667 had CFT titers of 1:1280. Serum alpha had a titer of 1:1280, serum beta was at 1:320 and serum gamma at 1:10. Pos. contr., serum from cow \#511 at day 70 (CFT titer of 1:320) post-infection.

characterised by the presence of a $70 \mathrm{kDa}$ antigen, corresponding to lipoprotein $\mathrm{LppB}$, which was not detected in European strains $[9,29]$. In addition, two other antigenic proteins have been characterised thus far in $M$. mycoides subsp. mycoides SC: the $72 \mathrm{kDa}$ antigen, also known as LppA $[8,16,17]$ and the 48-kDa protein LppQ [2]. In an attempt to characterise the other major antigenic protein bands, we identified the lppC gene. This gene encodes an immunogenic lipoprotein of $M$. mycoides subsp. mycoides SC corresponding to the antigenic band at
$39 \mathrm{kDa}$. The deduced amino acid sequence of LppC showed similarities with the two other known lipoproteins of $M$. mycoides subsp. mycoides SC, LppB [29] and LppQ [2]. This could explain why antibodies against the $\mathrm{N}$-terminal domain of $\mathrm{LppC}$ cross-react slightly with $\mathrm{LppB}$ which is present in the type strain and in African and Australian strains. The C-terminal parts of LppC and LppQ were also similar, consisting of five repeated units, rich in hydrophobic and aromatic amino acids in LppC, or nine of the same repeats in LppQ [2]. In 
analogy to LppQ, this structure found in $\mathrm{LppC}$ gives theoretical evidence for an integral membrane location [23]. The repeated amino acid motif might be involved in pore formation in the mycoplasmal membrane, building a channel for passive transport (inward and/or outward) of molecules through the membrane of $M$. mycoides subsp. mycoides $\mathrm{SC}$. The LppC protein was shown to be membrane-located by Triton $\mathrm{X}-114$ partitioning experiments and to harbour a single transmembrane region corresponding to the signal sequence. These data, together with the finding that recombinant LppC reacted strongly with the serum of cattle infected with $M$. mycoides subsp. mycoides SC, suggest that this lipoprotein is an outer membrane protein.

Southern blot and sequence analysis gave evidence for the presence of one complete copy of $\operatorname{lppC}$ and a further three partial copies of the same gene in the genome of M. mycoides subsp. mycoides SC. Two copies were interrupted by the insertion sequence IS1634 [28]. Most of the field strains tested, originating from Europe as well as from Africa and Australia, showed the same hybridisation profiles indicating that the different $\operatorname{lpp} C$ genes are on the same genetic loci in both African as well as European strains. Only one African field strain isolated from a zebu, the two vaccine strains $\mathrm{T} 1 / 44$ and $\mathrm{T} 1 / \mathrm{Sr} 50$, and the type strain presented unique patterns that may be explained by differences at the enzymatic cutting sites. Mycoplasma sp. bovine group 7 reference strain PG50 and the $M$. mycoides subsp. mycoides LC type strain Y-goat, both members of the M. mycoides cluster and closely related to $M$. mycoides subsp. mycoides SC, also revealed genes homologous to $\operatorname{lpp} C$.

Western blot analysis performed with anti-LppC serum and on whole cell antigen of several M. mycoides subsp. mycoides $\mathrm{SC}$ strains revealed a major band at $39 \mathrm{kDa}$ in all strains analysed as well as a minor band at $70 \mathrm{kDa}$ in non-European strains. This indicates that the mature LppC protein has an apparent molecular mass of $39 \mathrm{kDa}$ on SDS-PAGE. This value is significantly lower than the molecular mass calculated from the deduced amino acid sequence of the mature protein $(45.1 \mathrm{kDa})$, suggesting that LppC migrates abnormally on SDSPAGE. Such anomalous migration of mycoplasmal membrane proteins has been reported previously $[8,30]$. On the basis of the amino acid sequence, the most plausible explanation for this anomalous migration may be the potential for an unusual or denaturation-resistant protein conformation imparted by the particularly hydrophilic domain with charged residues. In this regard, it has to be noted that the calculated $\mathrm{pI}$ of the protein is 8.7. During an experimental infection, the cow infected with the African strain Afadé developed antibodies reacting with the recombinant protein LppCN'-His seven weeks postinfection, whereas the cow experimentally infected with the European strain L2 did not show any significant reaction until the time of slaughter. On the contrary, six sera from European cows that naturally acquired CBPP reacted strongly with LppCN'-His. The rather low serological response to LppC in an animal experimentally infected with the L2 strain reflects the generally low serological response of this animal to M. mycoides subsp. mycoides SC [1].

Genetic analysis revealed a TA repeat polymorphism upstream of the $\operatorname{lp} P C$ gene for several $M$. mycoides subsp. mycoides $\mathrm{SC}$ strains. This poly-TA locus is part of a palindromic sequence forming a hairpin structure and includes three of six bases within the potential -35 box and the entire putative -10 box of the $\operatorname{lpp} C$ gene. The different strains of $M$. mycoides subsp. mycoides SC revealed 8 to 18 TA repeats. It is interesting to note that these TA repeats are conserved although such a structure would be assumed to be lost, unless it is of functional importance, probably in the regulation of transcription. The possible -35 box found upstream of the $\operatorname{lpp} C$ gene presented a typical highly conserved prokaryotic sequence (TTGACA). The 
putative -10 box is also typical for prokaryotic organisms (TATAATG). Lipoprotein $\mathrm{Vmm}$ has recently been reported to undergo reversible phase variation, i.e., a reversible ON/OFF switch of expression [18]. DNA sequencing of the $v m m$ gene promoter from ON and OFF clones showed that the expression of Vmm is in fact regulated at the transcriptional level by TA insertions or deletions between the -35 and the -10 boxes. Clones that express Vmm and thus have an active promoter have been found to have ten such TA repeats. Any other number of repeats has been found to disrupt the functionality of the promoter [18]. In our case, however, all M. mycoides subsp. mycoides SC strains tested expressed LppC and showed no sectoring on immunostained colonies, indicating it as a stable antigen.

In conclusion, the $\operatorname{lpp} C$ gene appears to encode an important, stable antigenic lipoprotein of M. mycoides subsp. mycoides SC. The gene might have been multiplied and modified during evolution, reflecting the plasticity of mycoplasmal genomes.

\section{ACKNOWLEDGEMENTS}

We are grateful to Y. Schlatter for technical assistance with DNA sequence analysis. We thank L. Dedieu (CIRAD-EMVT, Montpellier, France) for efficient help in this project, F. Santini (Istituto Zooprofilattico Sperimentale dell'Abruzzo e del Molise, Teramo, Italy) and F. Thiaucourt (CIRAD-EMVT, Montpellier, France) for the gift of the strains.

This study was supported by the Swiss Ministry of Education and Science grant No. BBW99.0849 as part of the EU 5th Framework programme INCO, contract No. ICA4-CT2000-30015.

\section{REFERENCES}

[1] Abdo E.-M., Nicolet J., Miserez R., Gonçalves R., Regalla J., Griot C., Bensaide A., Krampe M., Frey J., Humoral and bronchial immune responses in cattle experimentally infected with Mycoplasma mycoides subsp. mycoides small colony type, Vet. Microbiol. 59 (1998) 109-122.

[2] Abdo E.-M., Nicolet J., Frey J., Antigenic and genetic characterization of lipoprotein LppQ from Mycoplasma mycoides subsp. mycoides SC, Clin. Diagn. Lab. Immunol. 7 (2000) 588-595.

[3] Ausubel F.M., Brent R., Kingston R.E., Moore D.D., Seidman J.G., Smith J.A., Struhl K., Current protocols in molecular biology, John Wiley \& Sons, Inc., New York, 1999.

[4] Bannerman E.S., Nicolet J., Isolation and identification of porcine Mycoplasma in Switzerland, Schweiz. Arch. Tierheilkd. 113 (1971) 697-710.

[5] Bordier C., Phase separation of integral membrane proteins in Triton X-114 solution, J. Biol. Chem. 256 (1981) 1604-1607.

[6] Brenner C., Wroblewski H., Le Henaff M., Montagnier L., Blanchard A., Spiralin, a mycoplasmal membrane lipoprotein, induces T-cell-independent B-cell blastogenesis and secretion of proinflammatory cytokines, Infect. Immun. 65 (1997) 4322-4329.

[7] Cheng X., Nicolet J., Poumarat F., Regalla J., Thiaucourt F., Frey J., Insertion element IS1296 in Mycoplasma mycoides subsp. mycoides small colony identifies a European clonal line distinct from African and Australian strains, Microbiology 141 (1995) 32213228.

[8] Cheng X., Nicolet J., Miserez R., Kuhnert P., Krampe M., Pilloud T., Abdo E.-M., Griot C., Frey J., Characterization of the gene for an immunodominant $72 \mathrm{kDa}$ lipoprotein of $\mathrm{Myc}$ oplasma mycoides subsp. mycoides small colony type, Microbiology 142 (1996) 35153524.

[9] Gonçalves R., Regalla J., Nicolet J., Frey J., Nicholas R., Bashiruddin J., DeSantis P., Gonçalves A.P., Antigen heterogeneity among Mycoplasma mycoides subsp. mycoides SC isolates: discrimination of major surface proteins, Vet. Microbiol. 63 (1998) 13-28.

[10] Harlow E., Lane D., Antibodies. A laboratory manual, Cold Spring Harbor Laboratory, New York, 1988.

[11] Herbelin A., Ruuth E., Delorme D., MichelHerbelin C., Praz F., Mycoplasma arginini TUH-14 membrane lipoproteins induce production of interleukin-1, interleukin-6, and tumor necrosis factor alpha by human monocytes, Infect. Immun. 62 (1994) 4690-4694.

[12] Hofmann K., Stoffel W., TMbase - A database of membrane spanning proteins segments, Biol. Chem. 374 (1993) 166-168. 
[13] Hubschle O., Lelli R., Frey J., Nicholas R., Contagious bovine pleuropneumonia and vaccine strain T1/44, Vet. Rec. 150 (2002) 615.

[14] Kyte J., Doolittle R.F., A simple method for displaying the hydropathic character of a protein, J. Mol. Biol. 157 (1982) 105-132.

[15] Laemmli U.K., Cleavage of structural proteins during the assembly of the head of bacteriophage T4, Nature 227 (1970) 680-685.

[16] Monnerat M.P., Thiaucourt F., Nicolet J., Frey J., Comparative analysis of the $\operatorname{lpp} A$ locus in Mycoplasma capricolum subsp. capricolum and Mycoplasma capricolum subsp. capripneumoniae, Vet. Microbiol. 69 (1999) 157-172.

[17] Monnerat M.P., Thiaucourt F., Poveda J.B., Nicolet J., Frey J., Genetic and serological analysis of lipoprotein LppA in Mycopasma mycoides subsp mycoides LC and $\mathrm{Myco}$ plasma mycoides subsp. capri, Clin. Diagn. Lab. Immunol. 6 (1999) 224-230.

[18] Persson A., Jacobsson K., Frykberg L., Johansson K.E., Poumarat F., Variable surface protein Vmm of Mycoplasma mycoides subsp. mycoides small colony type, J. Bacteriol. 184 (2002) 3712-3722.

[19] Pilo P., Fleury B., Marenda M., Frey J., Vilei E.M., Prevalence and distribution of the insertion element ISMag1 in Mycoplasma agalactiae, Vet. Microbiol. 92 (2003) 37-48.

[20] Provost A., Perreau P., Breard A., Le Goff C., Martel J.L., Cottew G.S., Contagious bovine pleuropneumonia, Rev. Sci. Tech. Off. Int. Epizoot. 6 (1987) 625-679.

[21] Rawadi G., Roman-Roman S., Mycoplasma membrane lipoproteins induce proinflammatory cytokines by a mechanism distinct from that of lipopolysaccharide, Infect. Immun. 64 (1996) 637-643.

[22] Regalla J., Caporale V., Giovannini A., Santini F., Martel J.L., Gonçalves A.P., Manifestation and epidemiology of contagious bovine pleuropneumonia in Europe, Rev. Sci. Tech. Off. Int. Epizoot. 15 (1996) 1309-1329.
[23] Reithmeier R.A., Characterization and modeling of membrane proteins using sequence analysis, Curr. Opin. Struct. Biol. 5 (1995) 491-500.

[24] Schaller A., Kuhn R., Kuhnert P., Nicolet J., Anderson T.J., MacInnes J.I., Segers R.P.A.M., Frey J., Characterization of apxIVA, a new RTX determinant of Actinobacillus pleuropneumoniae, Microbiology 145 (1999) 2105 2116 .

[25] Srivastava N.C., Thiaucourt F., Singh V.P., Sunder J., Isolation of Mycoplasma mycoides small colony type from contagious caprine pleuropneumonia in India, Vet. Rec. 147 (2000) 520-521.

[26] Valdivieso Garcia A., Rosendal S., Allen O.B., Thompson C.M., Watson S., Cytotoxicity of Mycoplasma mycoides subspecies mycoides for cultured endothelial cells, Int. J. Med. Microbiol. 272 (1989) 202-209.

[27] Vilei E.M., Frey J., Genetic and biochemical characterization of glycerol uptake in $\mathrm{Myco}$ plasma mycoides subsp. mycoides SC: Its impact on $\mathrm{H}_{2} \mathrm{O}_{2}$ production and virulence, Clin. Diagn. Lab. Immunol. 8 (2001) 85-92.

[28] Vilei E.M., Nicolet J., Frey J., IS1634, a novel insertion element creating long, variable-length direct repeats which is specific for Mycoplasma mycoides subsp. mycoides small-colony type, J. Bacteriol. 181 (1999) 1319-1323.

[29] Vilei E.M., Abdo E.-M., Nicolet J., Botelho A., Gonçalves R., Frey J., Genomic and antigenic differences between the European and African/Australian clusters of Mycoplasma mycoides subsp. mycoides SC, Microbiology 146 (2000) 477-486.

[30] Zheng X., Teng L.J., Watson H.L., Glass J.I., Blanchard A., Cassell G.H., Small repeating units within the Ureaplasma urealyticum MB antigen gene encode serovar specificity and are associated with antigen size variation, Infect. Immun. 63 (1995) 891-898. 